thebmi

\title{
Analysis
}

\section{Why combating tobacco smuggling is a priority}

BMJ 2008; 337 doi: http://dx.doi.org/10.1136/bmj.a1933 (Published 09 October 2008) Cite this as: BMJ 2008;337:a1933

Robert West, professor of health psychology 1 , Joy Townsend, emeritus professor of economics and primary care 2 , Luk Joossens, senior policy adviser ${ }^{3}$, Deborah Arnott, director 4 , Sarah Lewis, professor medical statistics 5

${ }^{1}$ Cancer Research UK Health Behaviour Research Centre, Department of Epidemiology and Public Health, University College London, London

${ }^{2}$ Public and Environmental Health Research Unit, London School of Hygiene and Tropical Medicine, London

${ }^{3}$ Framework Convention Alliance, Brussels, Belgium

${ }^{4}$ Action on Smoking and Health, London

${ }^{5}$ Department of Epidemiology and Public Health, University of Nottingham, Nottingham

Correspondence to R West robert.west@ucl.ac.uk

- Accepted 15 August 2008

Robert West and colleagues argue that reducing the amount of tobacco smuggled into the UK might prevent substantial numbers of premature deaths

Smuggled tobacco accounts for a sizeable proportion of consumption in the United Kingdom.1 Despite this, the UK dropped public targets for reducing tobacco smuggling in March this year. Responsibility for border controls is being passed from Her Majesty's Revenue and Customs to the new Border Agency, which has been asked to publish a strategy for tackling smuggling before this year's prebudget report. We present figures highlighting the serious effects of tobacco smuggling and suggest that the strategy should increase the effort and resources dedicated to reducing it.

\section{Smoking trends}

Prevalence of cigarette smoking in the UK is falling by about $0.4 \%$ a year but more needs to be done to speed the rate of decline. 2 Smoking remains the single largest preventable cause of premature death in the UK. Latest estimates put the prevalence of cigarette smoking at $22 \% .3$ However, the true figure may be higher as the $2 \%$ decline from the previous year was paralleled by a $2 \%$ decline in "ever smoking," which is not plausible. The 2006 Health Survey for England recorded a prevalence of $23 \%, 4$ but this could also be an underestimate because some smokers do not disclose that they smoke.5

The current fall in smoking prevalence coincided with the Labour government introducing a comprehensive tobacco control strategy in 1999. Actions included raising the price of tobacco through taxation; banning tobacco advertising; frequent publicity campaigns to promote cessation; and making treatments for nicotine dependence more widely available. 6 The implementation of indoor smoking 
bans in public places across the UK in 2006 and 2007 is expected to reduce prevalence further, although the experience of Ireland suggests that initial falls after the bans may be followed by some retrenchment.7 The UK already has one of the world's toughest tobacco control policies, 8 but greater action on smuggling might help cut smoking further.

\section{Smuggling and smoking}

From government statistics we estimate that $21 \%$ of tobacco consumed in the UK is smuggled, including 8.5 billion manufactured cigarettes and the equivalent of 7.27 billion own roll cigarettes. (This estimate excludes legal cross border shopping.) The price of smuggled products is about half of the duty paid equivalent.9 This means that the average price of tobacco would be about $11.6 \%$ higher were smuggling eliminated (box).

\section{Smuggling figures}

\section{How much tobacco is smuggled?1}

Total consumption of manufactured cigarettes in 2005-6: 63 billion

UK tax paid consumption of manufactured cigarettes: 49.5 billion

Illicit market in manufactured cigarettes: 8.5 billion

Cross border shopping of manufactured cigarettes: 5 billion

Total consumption of hand rolled tobacco (HRT) in 2005-6: 9700 tonne or at $0.75 \mathrm{~g} \mathrm{a}$ cigarette=12.9 billion cigarettes

UK tax paid consumption of HRT: 3200 tonne $=4.25$ billion cigarettes

Illicit market in HRT: 5450 tonne=7.27 billion cigarettes

Cross border shopping in HRT: 1050 tonne=1.4 billion cigarettes

Total consumption cigarettes and HRT: 63 billion +12.9 billion=75.9 billion

UK tax paid consumption: 49.5 billion +4.25 billion $=53.75$ billion ( $71 \%$ of total consumption)

Cross border shopping: 5 billion+1.4 billion=6.4 billion ( $8 \%$ of total consumption)

Illicit market: 8.5 billion +7.27 billion=15.75 billion ( $20.8 \%$ of the total consumption)

\section{What would be the effect of eliminating smuggling on the cost of smoking?}

The average price of smuggled cigarettes or tobacco has been estimated at half that of the duty paid counterpart

The aggregate price of tobacco currently is therefore: $79 \%$ at full price plus $20.8 \%$ at half price

Raising the cost of the $20.8 \%$ that is half price to full price would generate an aggregate 
price increase of $(20.8 / 2) /(79.2+20.8 / 2) \times 100=11.6 \%$

\section{What would be the effect of the increased cost of smoking on tobacco consumption?}

Elimination of smuggling would result in no price rise for the $79.2 \%$ of tobacco from the legal market but a $100 \%$ price rise for the $20.8 \%$ from the illicit market

Price elasticity is generally considered to follow a log-log function so that larger price increases do not result in proportionate reductions. The demand curve for an elasticity of -0.4 predicts that a $100 \%$ increase would result in a $24 \%$ fall in consumption

The reduction in consumption under this assumption would be expected to be about $20.8 \times 0.24=5 \%$. If the government's high elasticity of -0.72 is used, the reduction would be $8.2 \%)$

\section{What would be the effect of the decrease in tobacco consumption on the number of deaths?}

The number of deaths from smoking in the UK for 2002 is estimated at 114000

There is a lag of $15-20$ years between tobacco consumption and mortality, and mortality is currently declining because of falling tobacco consumption over the past 20 years. Cigarette consumption has fallen $30 \%$ in the past 20 years and so we could predict that the death rate from the current prevalence figure will be roughly $30 \%$ lower than the current death rate. This would put it at about 80000

If the number of deaths from tobacco is assumed to be roughly proportionate to aggregate consumption, other things being equal, a $5 \%$ reduction in consumption would result in 80 $000 \times 0.05$ fewer deaths, which is 4000

An $8.2 \%$ reduction (based on the government's high price elasticity estimate) would result in 6560 fewer deaths $(80000 \times 0.082)$

It is not known whether the reduction in consumption would arise from smokers reducing the amount they smoke or giving up altogether, or from young people not taking up smoking in the first place. It is likely that it would arise from a combination of all three, but this would make little difference to the calculations as smoking related mortality is proportional to both being a smoker and to the number of cigarettes smoked a day.

Estimates of price elasticity (the effect of price on demand for cigarettes) vary. The UK government uses a high estimate of -0.72 , which means that every $1 \%$ increase in price would result in a fall of $0.72 \%$ in consumption. 10 However, the figure most widely used for developed countries, including by the European Union and the World Bank, is -0.4. If we apply this figure to the demand curve (with the market segmented into legitimate and smuggled sources of tobacco) doubling the price of the $21 \%$ of tobacco purchased through smuggling would result in an overall $5 \%$ reduction in consumption, or $8.2 \%$ using the UK government's high estimate of elasticity (box). Although smokers may offset the increased cost of their smoking by trading down to discounted legitimate brands or by rolling their own cigarettes, these have always been options, and the elasticity estimates are derived from time series in which the 
option to trade down is present.

Estimates of the number of deaths averted by a given reduction in cigarette consumption again vary slightly according to the assumptions made, but these estimates converge narrowly to a future steady state figure of about 4000 for a reduction of $5 \%$. The government's high estimates of the elasticity of demand for tobacco would imply a potential reduction of at least 6500 deaths a year. These figures compare with about 1000 deaths each year from the use of all smuggled illicit drugs.11

Recent evidence shows that low income smokers are the most likely to use smuggled tobacco.12 This means reducing smuggling could reduce health inequalities.12 Low income smokers also seem more responsive than other smokers to price changes13; if they also smoke a disproportionate amount of smuggled tobacco, elimination of smuggling would result in an even larger reduction in smoking and premature deaths than we have estimated.

\section{Government action}

Any new strategy to reduce smuggling needs to include clear targets. When the new UK Border Agency takes over part of the responsibility for controlling smuggling later this year, it is crucial that responsibility for meeting targets for the reduction of smuggled tobacco becomes a shared responsibility between HM Revenue and Customs and the new agency. HM Revenue and Customs will remain responsible for setting policy and controlling smuggling inland so effective collaboration between the two bodies and joint targets will be essential.

The UK government has indicated support for the development of an illicit trade protocol for the WHO Framework Convention for Tobacco Control. This should be negotiated and brought into force as quickly as possible. The government should support the strongest possible protocol along the lines of the template produced by the WHO expert working group.14 This sets out comprehensive measures to control the illicit tobacco trade, including overt and covert marking of tobacco products so that they can be tracked and traced from manufacture to point of sale. These markings would enable identification of illicit products, including counterfeit ones, and also help determine the point at which tobacco products are diverted from the legal to the illicit market. The protocol also requires participants in the supply chain to be licensed so that they can be monitored effectively. Manufacturers would have to control the supply chain for their products, with serious financial penalties for those that fail to do so. In addition, enhanced law enforcement measures such as cooperation in investigation and prosecution of offences, information sharing, mutual legal assistance, and extradition arrangements would increase the ability of governments to work together to stop the illicit trade.

The UK government has not yet followed all other European Union countries and signed up to agreements to control supply with the tobacco companies Philip Morris International and Japan Tobacco International. These agreements are legally enforceable and include a requirement for the tobacco companies to tightly control and regulate the distribution system and to stop supplying contractors if they are found to be complicit in smuggling; marking systems allowing customs to independently identify smuggled cigarettes so that they can be traced back to the contractor who originally bought them from the company; and seizure payments. For the first 90 million smuggled cigarettes seized each year (the equivalent of nine $40 \mathrm{ft}$ (12.2 $\mathrm{m}$ ) container loads), the companies have to pay all taxes and duties due. For any additional amount seized they have to pay $500 \%$ of all taxes and duties due (which amounts on average to $€ 7.5 \mathrm{~m}$ ( $£ 6 \mathrm{~m} ; \$ 10.4 \mathrm{~m}$ ) for each additional container). These payments provide a strong financial incentive for the tobacco companies to control smuggling of 
their products.

Tobacco smuggling has reduced considerably since the government announced its first strategy to tackle it in 2000, but much more needs to be done. This will require a substantial increase in resources. There is a real risk that once the Borders Agency takes over responsibility for cross border control, with its main focus on immigration, tobacco smuggling will cease to be treated as the priority it needs to be.

\section{Notes}

Cite this as: BMJ 2008;337:a1933

\section{Footnotes}

- Contributors and sources: RW has been doing research in smoking for 25 years. JT has researched and published widely on tobacco control economics and policy. LJ has published several scientific articles on cigarette smuggling and advised the World Bank, the World Health Organization, the European Union, governments, and international and national organisations on combating cigarette smuggling. DA is a member of the Royal College of Physicians Tobacco Advisory Group. This article arose from discussions concerning where the UK government should place emphasis in the aftermath of the smoke-free legislation. RW conceived the article and prepared the first draft. JT contributed expertise on economic modelling. LJ contributed expertise and figures on smuggling. DE contributed expertise on policy and smuggling. SL contributed estimates of mortality. All authors contributed to development of the final version of the paper. RW is the guarantor.

- Competing interests: RW does research and consultancy for manufacturers of smoking cessation products.

- Provenance and peer review: Not commissioned; externally peer reviewed.

\section{References}

1. H M Revenue and Customs. Measuring indirect tax losses-2007. www.hmrc.gov.uk/pbr2007/mitl.pdf .

2. Jarvis MJ. Monitoring cigarette smoking prevalence in Britain in a timely fashion. Addiction2003;98:1569-74.

3. Goddard E. Smoking and drinking among adults, 2006: general household survey. London: Office of National Statistics, 2007.

4. National Statistics. Health survey for England 2006. London: Stationery Office, 2008.

5. West R, Zatonski W, Przewozniak K, Jarvis MJ. Can we trust national smoking prevalence figures? Discrepancies between biochemically assessed and self-reported smoking rates in three countries. Cancer Epidemiol Biomarkers Prev2007;16:820-2.

6. Department of Health. Smoking kills: a white paper on tobacco. London: Stationery Office, 1999.

7. Action on Smoking and Health. Impact of smoke-free legislation in Ireland. 2006. http://old.ash.org.uk/html/publicplaces/html/irelandimpact.html.

8. Joossens L, Raw M. the tobacco control scale: a new scale to measure country activity. Tob Contro/2006;15:247-53.

9. Chief medical officer. Annual report of the chief medical officer on the state of public health. London: 
Department of Health, 2005.

10. Cullum P, Pissarides CA. The demand for tobacco products in the UK. London: HM Revenue and Customs, 2004.

11. Office of National Statistics. Deaths related to drug poisoning, England and Wales, 2005. London: ONS, 2007.

12. Action on Smoking and Health. Beyond smoking kills. London: ASH, 2008.

13. Townsend J, Roderick P, Cooper J. Cigarette smoking by socioeconomic group, sex and age: effects of price, income and health policy. BMJ1994;309:923-7.

14. World Health Organization. Elaboration of protocols (decision FCTC/COP1(16). Elaboration of a template for a protocol on illicit trade in tobacco products. Geneva: WHO, 2007. 